Please cite as: Greifeneder, R., Müller, P., Stahlberg, D., Van den Bos, K., \& Bless, H. (2011). Guiding Trustful Behavior: The Role of Accessible Content and Accessibility Experiences. Journal of Behavioral Decision Making, 24, 498-514. doi: 10.1002/bdm.705

Address correspondence to: rainer.greifeneder@unibas.ch

Guiding Trustful Behavior:

The Role of Accessible Content and Accessibility Experiences

Rainer Greifeneder, ${ }^{1,2}$ Patrick Müller, ${ }^{3}$

Dagmar Stahlberg, ${ }^{2}$ Kees van den Bos, ${ }^{3}$ and Herbert Bless ${ }^{2}$

${ }^{1}$ Radboud University Nijmegen, The Netherlands

2 University of Mannheim, Germany

${ }^{3}$ Utrecht University, The Netherlands 


\begin{abstract}
Trust has been identified as a key ingredient to the prosperity of close relationships, organizations, and societies. While research mainly focused on the antecedents and consequences of trust, much less is known about how individuals assess whether there are enough reasons to warrant trustful action. Two experiments explored the how and when of this assessment, suggesting that antecedents may not only be integrated as content information per se (as generally assumed), but in a feeling-based summary form. Specifically, our results show that the ease or difficulty associated with the identification of antecedents to trust may guide trustful behavior. Furthermore, it is shown that such a feeling-based influence is particularly likely to occur in conditions of personal certainty. Together these results extend prior research in the domains of trust and economic games, and further attest to the fundamental role cognitive feelings play in social life.
\end{abstract}

Keywords: Trust; Accessibility Experience; Ease-of-retrieval; Feelings; Uncertainty 


\section{Guiding Trustful Behavior: \\ The Role of Accessible Content and Accessibility Experiences}

Trust is one of the fundamental building blocks of social life. It is vital for the functioning of close relationships and organizations (Kramer, 1999), as well as for the political (Fukuyama, 1995 ) and economic prosperity of societies (Knack \& Keefer, 1997). In fact, trust has been suggested to be a key problem of human adaptation and survival (Griffin, 1992). Following these observations, it comes at no surprise that trust is an interdisciplinary research topic, with theorizing and evidence obtained in philosophy, economics, and social sciences. Especially in political and economic crisis, this research is met with widespread interest.

Much of prior research has focused on the defining characteristics of trust as well as its antecedents (e.g., Dirks \& Ferrin, 2001; McKnight et al., 1998). Empirical investigations as to antecedents revealed, for instance, that perceptions of procedural justice help individuals to feel assured and build up expectations about future transactions, thus enabling trust (Van den Bos et al., 1998). Less is known, however, about how such antecedents are integrated to form intentions for trustful behavior. The present research focuses on this important question, suggesting that antecedents may not only influence trust and trustful behavior as to be integrated single pieces of content information-the default assumption—but in summary form, as feeling experiences. Specifically, we propose that accessibility experiences associated with the identification of antecedents (e.g., "it feels easy to identify reasons for this being a fair procedure") may guide trustful behavior. In what follows, we elaborate on this hypothesis.

\section{Trust and trustful behavior}

Following Mayer, Davis, and Schoorman (1995), we define trust as the intention of an individual—henceforth called the trustor-to depend on another person—henceforth called the trustee- based on a set of believes about the trustee. Central to this definition are two 
components: trusting beliefs, that is, expectations that the trustee will behave or perform in a specific way, and trusting intentions, that is, the trustor's willingness to depend on the trustee and make her- or himself vulnerable to her or his actions. The trustor accepts that he or she might suffer, for instance, a loss, an injury, or harm, as a consequence of trusting the trustee. This definition focuses on the willingness to incur this risk; actually assuming this risk-trustful behavior-is defined as the outcome variable. This outcome variable reflects the (prior) presence of trust and is often used to operationalize trust (e.g., Berg et al., 1995), resulting in a situation where the two concepts, trust and trustful behavior, are often referred to synonymously. What are the antecedents of trust? What will make individuals depend on others, to put themselves at risk such as potential exploitation or exclusion (Lind, 2001)? Three groups of factors have been differentiated (e.g., Mayer et al., 1995). First, characteristics of the trustor influence trust. For instance, Rotter (1966) suggested that some individuals dispositionally tend to trust more than others. This generalized trust reflects what may be labeled individual naïve theories on the functioning of relationships, organizations, and societies.

Second, factors associated with the trustee influence trust. Mayer and colleagues (1995) group according variables in the categories of ability, benevolence, and integrity. Ability enables a trustee to act in the trusted way; benevolence reflects a positive orientation towards the trustor; integrity is defined as the adherence to a set of values or principles that are acceptable to the trustor.

Third, contextual variables influence trust. For instance, the stakes and the risks associated with trusting are important determinants of trust, as well as the perceived likelihood that a certain behavior results in certain outcomes (e.g., Mayer et al., 1995; McKnight et al., 1998). Situation variables are especially important for the formation of initial trust, when little is known about the trustee (McKnight et al., 1998). 
All three kinds of antecedents-factors associated with the trustor, the trustee, and the situation—may work together. For instance, a trustor may perceive a trustee as able, benevolent, and integer, and the situation as such that potential benefits justify risks. Based on this assessment, the individual may decide that there are enough reasons to trust, and to act trustfully.

But how does this assessment of "enough reasons" come about? Do individuals integrate the identified antecedents per se, as content information, such as by counting and/or weighing? Or, as we hypothesize, do individuals rely on a feeling-based summary assessment, such as "identifying these antecedents felt pretty easy," based on which they subsequently form inferences, such as "there are probably enough reasons to trust?" After all, if the antecedents come easily to mind, there are probably many of them, suggesting that trustful behavior may be warranted. Although such feeling-based inferences may not appear intuitive on first glance, they have received considerable support in other domains of research, as we detail in what follows.

\section{Cognitive feelings}

Judgments and decisions were long presumed to be based solely on content information, such as arguments in favor or against a specific position. In case of trust, this would mean that risk judgments are dependent only on the mere content of what is known, for instance, about the stakes and risks in a given situation. However, over the last thirty-five years, this content-only assumption has been strongly challenged by evidence showing that judgments may also be formed on the basis of feelings (Schwarz \& Clore, 2007). For instance, Schwarz and colleagues (1991) reported that the felt ease or difficulty with which information can be retrieved from memory influences judgments about the self. Such feelings constitute an independent source of information that individuals may use in addition to, or instead of, content information to form judgments (e.g., Schwarz \& Clore, 2007). Because these feelings of ease or difficulty are 
associated with cognitive processing, but felt much like affective or bodily feelings are, they are generally referred to as "cognitive feelings" (Clore, 1992).

While affective feelings are referred to often in everyday language, feelings associated with cognitive processes (i.e., cognitive feelings; Clore, 1992) are less frequently talked about. However, this does not mean that individuals are not familiar with such phenomena. For instance, most people have experienced tip-of-the-tongue states (Schwartz, 2002), in the course of which they feel that they know a certain piece of information such as a word or name, but are currently unable to access it (see also Koriat, 1993). Likewise, most individuals are used to feelings of familiarity (Whittlesea, 1993), in the course of which they feel that they have encountered some person or object before, but are currently unable to specify this encounter; such as when riding on a bus and having the feeling that the person sitting next to them is familiar, yet without realizing that this is the clerk from the local supermarket. In both examples, content information is currently inaccessible, but cognitive feelings indicate its presence. Reflecting this critical role, cognitive feelings have been termed a "window to the unconscious" (Koriat \& Levy-Sadot, 1999; Whittlesea \& Leboe, 2000), which individuals appear to frequently peek through, though not necessarily being aware of doing so.

One particularly important characteristic of cognitive feelings is that they integrate a wide variety of inputs and details into a single whole (e.g., Nowlis \& Nowlis, 1956; Pribram, 1970). Cognitive feelings are therefore conceptualized as meta-summaries of activated information (Clore \& Parrott, 1994; Koriat \& Levy-Sadot, 1999). Compared to single pieces of content information, which need to be integrated to form a judgment, feelings are ready-made summaries, which can be directly used as input for judgments and decisions (Schwarz \& Clore, 2007). Presumably it is this summary characteristic that renders feelings not a definite source of error, but a generally sensible information basis (Greifeneder et al., 2010; Schwarz et al., 2008). 
A particular prominent example amongst cognitive feelings is the experience of ease or difficulty when retrieving content information from memory. These experiences have been variously denominated as ease-of-retrieval or accessibility experiences (Schwarz et al., 1991; for reviews, Schwarz, 1998; 2004). Research on accessibility experiences initially focused on frequency judgments, demonstrating that the frequency of some object is judged to be higher the more easily according examples can be retrieved from memory (Tversky \& Kahneman, 1973). Later contributions revealed that accessibility experiences influence judgments and decisions in many other domains. For instance, judgments about the self (e.g., Greifeneder \& Bless, 2008; Schwarz et al., 1991) and others (e.g., Dijksterhuis et al., 1999; Haddock, 2002) are the more positive the more positively valued self- or other-relevant information can be retrieved easily. Similarly, judgments about objects reflect the ease or difficulty with which according pieces of information can be brought to mind (e.g., Novemsky et al., 2007). And even abstract concepts such as health-related risks (Raghubir \& Menon, 1998), attitude strength (Haddock et al., 1999), or memory performance (e.g., Winkielman et al., 1998), are influenced by accessibility experiences. Finally, accessibility experiences may also directly influence behavior (Keller \& Bless, 2005; Müller et al., in press).

To the best of our knowledge, however, it has not been investigated whether accessibility experiences may also guide trust and trustful behavior. This is surprising, as cognitive feelings have been suggested to be a generally valid source of information that individuals frequently rely on (Greifeneder et al., 2010; Schwarz et al., 2008). Moreover, accessibility experiences are known to influence concerns about procedural justice (Greifeneder et al., 2009), an important antecedent of trust (Van den Bos et al., 1998). Accordingly, it seems plausible that the impact of accessibility experiences may not stop at beliefs, but extend to intentions and behavioral manifestations of trust. 
Uncertainty moderates the impact of accessibility experiences

Assuming that both content information per se (e.g., specific arguments) and associated accessibility experiences may influence trustful behavior, it is important to understand when the one and when the other is likely to occur (e.g., Spencer et al., 2005). In this respect, we hypothesize that personal uncertainty-the subjective sense of doubt or instability that arises when a person experiences unclear or inconsistent self-relevant cognitions (cf. McGregor et al., 2001)—moderates the influence of accessibility experiences versus accessible content information on trustful behavior. Specifically, we hypothesize that accessibility experiences exert a direct influence on trustful behavior in conditions of personal certainty, whereas content information is likely to be of impact in conditions of personal uncertainty. This is because personal uncertainty constitutes an uncomfortable and often aversive state, that individuals strive to cope with (Hogg, 2005; Lopes, 1987; Van den Bos \& Lind, 2002). One possibility for coping is to accord particular relevance to fairness information (e.g., De Cremer \& Sedikides, 2005). After all, when treated in a fair way, individuals are less uncertain about themselves (Van den Bos et al., 2006) and better able to tolerate the uncertainties they are experiencing (Greenberg, 2006). Personal uncertainty may thus increase the relevance of justice-related concerns, and this heightened relevance is likely to trigger systematic elaboration of the available content information, as suggested in many dual-process theories (see contributions in Chaiken \& Trope, 1999). In contrast, for personally certain individuals, justice-related concerns may be relatively less relevant, and individuals may thus be expected to resort to less effortful processing strategies, such as relying on accessibility experiences (e.g., Tversky \& Kahneman, 1973). Attesting to this reasoning, prior research revealed that accessibility experiences are particularly likely to be relied upon in conditions of low processing motivation (e.g., Rothman \& Schwarz, 1998). 
At first glance, the prediction that the impact of accessibility experiences is particularly pronounced in conditions of personal certainty may appear to clash with the work on "judgments under uncertainty" (Tversky \& Kahneman, 1974), which holds that judgmental heuristics in general, and reliance on accessibility experiences in particular, are likely to be relied upon in situations of uncertainty. Yet, this contradiction is not really genuine, as the opposing predictions integrate very well if one looks more closely at the different types of uncertainty addressed. The present contribution focuses on personal uncertainty, that is, the "subjective sense of doubt or instability in self-views, world-views, or the interrelation between the two" (Van den Bos \& Lind, in press, p. 5). In contrast, prior work in the domain of decision making often focused on uncertainty resulting from ambiguity or a lack of information, which has been referred to as informational uncertainty and is characterized by incomplete information (see Van den Bos \& Lind, in press). In conditions of informational uncertainty, content information may be perceived as undiagnostic, and individuals may recur to other, seemingly unrelated sources of information, like cognitive feelings. In conditions of personal uncertainty, however, individuals may not harbor doubts about the validity of retrieved content information, because the experienced uncertainty is not related to the informational basis. Accordingly, in conditions of personal uncertainty-as addressed in the present studies—content information is likely to influence trustful behavior.

In sum, we hypothesize that uncertainty moderates whether trustful behavior is guided by accessibility experiences versus accessible content. Specifically, we expect that accessibility experiences guide trustful behavior in conditions of personal certainty, whereas accessible content information guides trustful behavior in conditions of personal uncertainty.

While our main hypothesis, the predicted moderation, is expected to translate in a significant disordinal pattern of results, it is less clear how strong the simple effects of reliance on accessibility experiences versus content information will be. Recent theorizing and evidence suggests that reliance on feelings is a pervasive phenomenon, in fact much more pervasive than 
often assumed (e.g., Pham, 2008; Schwarz \& Clore, 2007). One may thus generally expect a reliable impact of accessibility experiences. This effect should be counteracted the more individuals rely on the activated content, as expected in conditions of personal uncertainty. Yet, whether this counteracting leads to a reliable reversal of the effect or only to a reliable reduction of the accessibility impact is more difficult to predict, because the extent of this counteracting depends on how strongly the moderating variable is subjectively experienced. Given this a priori latitude, we confine statistical predictions to the theoretically relevant moderation finding per se, and examine the simple effects of reliance on accessibility versus content information in explorative fashion only.

\section{Overview of experiments}

To operationalize trust, we relied on the trust game (Berg et al., 1995). In this sequential economic game, a participant-the trustor or sender-must first decide how much of a given endowment she or he transfers to another participant-the trustee or receiver. This amount is then multiplied by some factor (e.g., quadrupled). In a second step, the receiver decides whether and how much money he or she returns to the sender. This return amount is not multiplied. If both sender and receiver display trust, both will end up with a higher monetary payoff. However, if only the sender trusts, but the receiver abuses trust, then the sender will take a loss. As both sender and receiver are anonymous and have no interaction history, a rational and selfish receiver should never send money back. Expecting this, a rational sender should never send money in the first place, resulting in a Nash equilibrium of no transaction. Despite these pessimistic predictions, research shows that the majority of senders decides to send at least some amount, thereby rendering him- or herself vulnerable to the actions of the receiver. The transferred amount (the outcome variable) is therefore an indicator of trust (Berg et al., 1995). 
Given anonymity of the receiver, trust in the trust game should be mainly a function of the trustor's disposition and situational variables. We focused participants' attention on the latter, specifically on the perceived fairness of the procedure, because procedural fairness has been identified as a powerful antecedent of trustful behavior (Van den Bos et al., 1998).

To investigate how individuals integrate information about antecedents to trust, we employed a paradigm introduced by Schwarz and colleagues (1991). This paradigmhenceforth referred to as accessibility experiences paradigm—sets the judgmental stage in such a way that opposing results emerge from reliance on content information versus reliance on accessibility experiences. To illustrate, consider Schwarz and colleagues' (1991) original study, in which participants were asked to recall few versus many instances of previous unassertive behavior, and then to judge their own assertiveness. When relying on content information, the recall of many as compared to few examples should result in lower perceptions of assertiveness. After all, many instances of prior unassertive behavior seem indicative of low assertiveness. When relying on accessibility experiences, however, the recall of many examples—which is experienced as difficult—as compared to few examples—which is experienced as easy—should result in higher ratings of assertiveness. After all, when recalling instances of unassertive behavior is difficult (easy), it would appear that unassertive behavior was uncommon (common), which seems indicative of high (low) assertiveness. The accessibility experiences paradigm thus allows for the critical differentiation between content- versus experience-based effects, and, hence, for testing moderation. ${ }^{1}$

Applying the accessibility experiences paradigm to the realm of trust, we asked participants to identify few-which is experienced as easy—versus many—which is experienced as difficult—unfair aspects of the trust game procedure. If participants rely on content information, they will perceive the trust game as less just and display less trustful behavior after identifying many as compared to few unfair aspects. In contrast, if participants rely on 
accessibility experiences, they will evaluate the procedure as more just and display more trustful behavior after identifying many (difficult) as compared to few (easy) unfair aspects. After all, if it is difficult to come up with unfair aspects, there cannot be many of them; hence the procedure is probably just, and trusting is possible. Conversely, if it is easy to come up with unfair aspects, chances are that there are many of them; hence, the procedure cannot be just, and trusting would appear not recommended. A concise overview of these conjectures is provided in Table 1.

It is important to acknowledge that, as in other research (e.g., Berg et al., 1995), we conjecture (but do not measure) trust. Rather, accessibility experiences are related to the antecedents of trust, and the trust game assesses outcomes of trust. Trust is assumed to be present in between.

\section{Experiment 1}

Experiment 1 used a scenario version of the trust game (e.g., Buchan \& Croson, 2004). To manipulate accessibility experiences, participants were asked to think of either few (easy) or many (difficult) unfair aspects of the trust game. Personal uncertainty was manipulated by varying the salience of uncertainty-related thoughts (procedure adapted from Van den Bos, 2001). We hypothesized that trustful behavior will be guided by accessibility experiences, but only in conditions of personal certainty.

\section{Method}

\section{Participants}

Sixty University of Mannheim students voluntarily participated in an experiment labeled "Pre-study for a decision-making experiment." Participants received 1 Euro and a chocolate bar 
(total 1.30 USD) as compensation. Thirty-eight percent of participants were females, and the mean age was 21.8 years $(S D=2.3)$.

\section{Design and Procedure}

Participants were randomly assigned to a 2 (few vs. many unfair aspects) $\times 2$ (uncertainty salient vs. certainty salient) factorial design. Participants were told about the specifics of the trust game and learned that they and another anonymous player, with whom they have no interaction history, receive a hypothetical endowment of 10 Euros each. Participants were asked to imagine that they are the sender, who has to act first. It was stressed that the situation was hypothetical and that participants would receive a fixed compensation independent of the decision in the scenario.

Until this point all participants had the same instructions, and therefore got to know the trust game the same way. Only then accessibility experiences were manipulated by asking participants to identify either two or four aspects of the game that seemed unfair to them as senders. Independent pre-testing had revealed that recalling two unfair aspects of the game was perceived as easy, whereas recalling four unfair aspects was perceived as difficult.

To manipulate the salience of personal uncertainty versus certainty (henceforth generically referred to as manipulation of personal uncertainty), participants were then asked to imagine being someone who feels uncertain (certain), and to respond to the following two questions: "What emotions does the thought of your being uncertain (certain) about yourself arouse in you?," and "What will happen physically to you as you feel uncertain (certain) about yourself?" (Van den Bos, 2001). Note that personal uncertainty was manipulated after the manipulation of accessibility experiences to rule out potential order effects of uncertainty on accessibility experiences (see Greifeneder \& Bless, 2007, for why this order of manipulations is critical). 
Finally, procedural fairness perceptions, trusting behavior, manipulation checks, and demographic information were assessed. Participants were paid, debriefed, and thanked for their participation.

\section{Dependent variables}

Procedural fairness perceptions. Procedural fairness perceptions were assessed by asking participants to indicate their agreement with the following three statements: "From the perspective of the sender, the game is unfair.;" "From the perspective of the sender, the procedure is just.;" and "The procedure of the game is appropriate from the perspective of the sender." Answers were given on 9-point rating scales (1, does not apply, to 9, does apply).

Trustful behavior. Participants were asked to indicate how much money they would entrust to the receiver. Participants could transfer between zero and ten Euros, in 1-Euro increments.

Accessibility experiences. Serving as a manipulation check, participants were asked "How easy or difficult was it to list unfair aspects of the game?;" and "How easy or difficult would it have been for you to list more unfair aspects?" Answers were given on 9-point rating scales (1, very difficult, to 9 , very easy).

Personal (Un)certainty. To test whether the manipulation of personal uncertainty influenced the frequency of uncertainty and certainty related thoughts, participants were asked whether (1, definitely did not, to 7 , definitely did) and to what extent (1, very weak, to 7 , very strong) they had been thinking about uncertainty, and whether (1, definitely did not, to 7 , definitely did) and to what extent (1, very weak, to 7 , very strong) they had been thinking about certainty, while writing down their answers (for a similar measure, see Van den Bos et al., 2005). 


\section{Results}

\section{Preliminary analyses}

Accessibility experiences. The two items assessing accessibility experiences were averaged to form a single index (Cronbach's $\alpha=.75$ ), which was entered into a 2 (few vs. many unfair aspects) $\times 2$ (uncertainty salient vs. certainty salient) ANOVA. As expected, identifying two unfair aspects was experienced as easier than identifying four unfair aspects $(M=3.35$, $S D=2.09$ vs. $M=2.20, S D=1.60), F(1,56)=5.67, p<.03$. Accessibility experiences were unaffected by the-later instigated—manipulation of personal uncertainty (main and interaction effects, Fs $<1.01)$.

Personal (un)certainty. The two items assessing the salience of uncertainty-related thoughts (Cronbach's $\alpha=.84$ ) and the two items assessing certainty-related thoughts (Cronbach's $\alpha=.83$ ) were each averaged to form two separate measures, which were then jointly entered in a 2 (few vs. many unfair aspects) $\times 2$ (uncertainty salient vs. certainty salient) multivariate analysis of variance (MANOVA). Only a main effect of the salience manipulation at both the multivariate level and the univariate levels was found: multivariate $F(2,55)=11.54$, $p<.01$; for the uncertainty measure, $F(1,56)=4.66, p<.04$; for the certainty measure, $F(1,56)=21.33, p<.01$. As expected, personal uncertainty was more salient in the uncertainty condition $(M=5.23, S D=2.12)$ than in the certainty condition $(M=4.00, S D=2.22)$. Similarly, personal certainty was more salient in the certainty condition $(M=6.17, S D=1.96)$ than in the uncertainty condition $(M=3.92, S D=1.81)$.

Procedural fairness. The three items targeting procedural fairness perceptions were scaled such that higher values reflect higher fairness, averaged to form a single index (Cronbach's $\alpha=.81$ ), and entered into a 2 (few vs. many unfair aspects) $\times 2$ (uncertainty salient vs. certainty salient) ANOVA. There was neither a main effect of uncertainty salience, $F<1$, nor 
a main effect of number of aspects, $F(1,56)=1.89$, ns. However, the interaction between number of aspects and salience was significant, $F(1,56)=4.60, p<.04$. Participants in the certainty salient condition expected the procedure to be less fair after identifying few rather than many aspects $(M=3.53, S D=1.74 ; M=5.16, S D=2.11), t(56)=-2.49, p<.01$. In line with prior evidence (Schwarz et al., 1991), this pattern suggests that participants relied on accessibility experiences when forming fairness perceptions. This conclusion is further supported by correlational evidence, revealing a negative relationship between accessibility experiences and procedural fairness perceptions, $r=-.36, p<.05$. In contrast, in conditions of uncertainty salience, the procedure was perceived as similarly fair regardless of the number of unfair aspects identified $(M=4.38, S D=1.50 ; M=4.02, S D=1.73$, for few vs. many aspects, respectively), $|t|<1$. Presumably, this reflects that self-uncertain participants did not use accessibility experiences as a source for judgment formation, but, at least as a tendency, integrated content information. Again, this conclusion is corroborated by correlational evidence, as there is no reliable relationship between accessibility experiences and judgments, $r=-.07, n s$. These findings suggest that the manipulation of accessibility experiences successfully created conditions in which an important situational antecedent to trust—procedural fairness—is perceived differently, thus setting the stage for differential levels of trustful behavior.

\section{Test of hypotheses}

Our main dependent variable was the amount of money entrusted to the receiver. This variable was entered into a 2 (few vs. many unfair aspects) $\times 2$ (uncertainty salient vs. certainty salient) ANOVA. In line with our main hypothesis, the interaction between number of aspects and salience was significant, $F(1,56)=4.72, p<.04$. Figure 1 illustrates that certainty salient participants trusted less money to the other player after identifying few as compared to many unfair aspects $(M=4.33, S D=2.77 ; M=6.27, S D=3.67), t(56)=-1.75, p<.05$, one-tailed. This 
finding suggests that trustful behavior in conditions of personal certainty was guided by accessibility experiences. Conversely, for participants to whom uncertainty was made salient, the effect was reversed $(M=7.07, S D=2.40 ; M=5.60, S D=3.14), t(56)=1.33, p<.10$, onetailed. Presumably, this pattern reflects that trustful behavior in conditions of personal uncertainty was guided by the integration of content information. The main effects of uncertainty salience, $F(1,56)=1.89$, ns, and number of aspects, $F<1$, were not significant.

Additionally, we analyzed the relationship between procedural fairness and entrusted money. In line with the idea that procedural justice is an important antecedent of trustful behavior, this analysis revealed a positive correlation between the two constructs, $r=.26$, $p<.05$, suggesting that participants who perceived the procedure as fairer entrusted more money to the hypothetical receiver.

\section{Discussion}

Results of Experiment 1 suggest that individuals may integrate antecedents in a feelingbased summary form to decide about trustful behavior. Specifically, it was shown that accessibility experiences associated with the identification of antecedents to (dis-)trust influenced participants' trustful behavior. Moreover, in line with hypotheses, this occurred particularly in conditions of personal certainty, but less in conditions of personal uncertainty, in which participants, at least as a tendency, were found to integrate identified antecedents as content information.

While the results observed in Experiment 1 offer consistent support for the outlined hypotheses, one may argue that the hypothetical nature of Experiment 1 led participants to indicate unreasonable amounts of entrusted money. After all, there is a difference between just imagining to be dependent on an unknown other, or to be really so. Partly refuting this argument, the mean amount of money hypothetically transferred in the present experiment $(M=5.82$, of 
10 Euros) closely matches the amount of money transferred in the original study (5.36 of $\$ 10$; Berg et al., 1995). Furthermore, prior research has successfully relied on scenario versions of the trust game, too (e.g., Buchan \& Croson, 2004). Nevertheless, to strengthen the reported findings, participants in Experiment 2 were endowed with real money.

\section{Experiment 2}

Experiment 2 was designed to replicate the findings of Experiment 1 with some adaptations, moving the trust game closer to a simultaneous single-trial prisoners' dilemma used in previous research (cf. Van Lange, 1999, Exp. 3). Specifically, two major changes were introduced: First, participants played the game for real money with other participants. Also, participants did not receive a fixed amount of money for their participation as in Experiment 1 , but were compensated based on the game's outcome. Second, for practical reasons, participants were initially endowed with only 2 EUR (instead of 10 EUR), and the amount of money that participants send to the other player was doubled (instead of quadrupled). As before, sender and receiver were anonymous and were said to have no interaction history.

To attest to the generalizability of the reported results, uncertainty was not manipulated as in Experiment 1, but assessed as a dispositional measure. For this purpose, participants' social comparison orientation was measured (Gibbons \& Buunk, 1999), because, in social situations, one major source of uncertainty is the lack of knowledge about the appropriateness of one's own behaviors and cognitions. One possible way of resolving this uncertainty is to compare oneself to relevant others (e.g., Festinger, 1954). Consequently, a high need to compare oneself to others can be seen as an indicator for a high level of personal uncertainty (Thau et al., 2007). We hypothesized that trustful behavior of individuals with low social comparison orientation, and therefore low personal uncertainty, would be guided by accessibility 
experiences. In contrast, trustful behavior of individuals with high social comparison orientation, and therefore high personal uncertainty, should reflect the integration of antecedents as content information.

Method

Participants

Sixty-two University of Mannheim students participated in return for a variable amount of compensation. Fifty-nine percent of participants were female, and participants' mean age was 22.7 years $(S D=3.4)$. Three participants did not list any unfair aspects of the game and three participants did not work on the questionnaire assessing social comparison orientation. These six participants (three from each experimental group) were excluded from further analyses.

\section{Design, Procedures, and Materials}

Participants were randomly assigned to one of two experimental groups (few vs. many unfair aspects). Participants were seated in separate cubicles and each participant received an envelope, 2 Euro in 10 Eurocent coins, and a first questionnaire which included a description of the trust game. Participants were instructed to read this description carefully. They learnt that they would be randomly linked to another participant who would be their counterpart in the game. They were further informed that the 2 EUR now belonged to them and that they could freely decide what to do with it. They then read that they could entrust money to the other player-who had received the same amount of money—by putting money in the envelope, writing a personal code on this envelope, and depositing the closed envelope in an urn outside the experimental room. A second experimenter, unknown to and unseen by participants, would then take the envelope of the participant and her or his counterpart, double the amounts of entrusted money, and put these amounts in the respective other envelope. By way of this, 
participants would receive the double amount of money their counterpart had entrusted in them. All participants were carefully informed that the transfers took place simultaneously, and that the envelopes would be exchanged by the second experimenter. This procedure granted participants full anonymity with respect to the other player as well as the experimenter in charge of the payment, so as to reduce social desirability effects. Participants were told to retrieve the envelope with their code at the end of the experiment.

After these instructions, but before participants decided about the money to be transferred, accessibility experiences were manipulated as in Experiment 1 . Independent pretesting at the University of Mannheim had revealed that this version of the trust game was generally perceived as fairer than the scenario version in Experiment 1, supposedly because participants were not either sender or receiver, but all were in the same position. As a direct consequence, identifying unfair aspects was generally perceived as more difficult. We therefore decided to ask for one or three (instead of two or four, as in Experiment 1) unfair aspects. Further pre-testing confirmed that identifying one aspect was perceived as considerably easier than identifying three aspects.

Subsequently, and as in Experiment 1, procedural fairness perceptions were assessed, and participants were asked to decide about the money to transfer to the other player. All participants put an envelope into the urn and then returned to their cubicle. Participants then received a second questionnaire which included the manipulation check and Gibbons and Buunk's (1999) 11-item measure of social comparison orientation, which assesses the extent to which individuals compare their own opinions, abilities, and general aspects to those of others. Example items are: "I always pay a lot of attention to how I do things compared with how others do things." and "I always like to know what others in a similar situation would do." Answers were given on 5-point scales (1, strongly disagree, to 5, strongly agree). The second questionnaire 
closed with demographic variables. Participants were debriefed, thanked for their participation, and reminded to pick up their envelope outside the laboratory.

Results and Discussion

\section{Preliminary analyses}

Accessibility experiences. The two items assessing accessibility experiences were averaged to form a single index (Cronbach's $\alpha=.83$ ). As expected, identifying one as compared to three unfair aspects was experienced as easier $(M=4.35, S D=2.37 \mathrm{vs} . M=3.16$, $S D=2.17), t(53)=1.94, p<.06$.

Personal uncertainty. The 11-items used to operationalize dispositional personal uncertainty were averaged (Cronbach's $\alpha=.75$ ). This measure was not significantly different for participants who identified one versus three unfair aspects $(M=4.49, S D=0.76$ vs. $M=4.62$, $S D=0.80),|t|<1$, suggesting that the experimental manipulation did not differentially impact participants' dispositional uncertainty.

Procedural fairness. The three procedural fairness items were averaged (Cronbach's $\alpha=.78$ ) and entered as dependent variable in a hierarchical regression analysis. Number of aspects and the centered score of personal uncertainty were entered as predictors in Step 1, the interaction term was entered in Step 2. Procedural fairness perceptions were predicted by neither the number of aspects, $\beta=-0.20, t(51)=-1.55$, ns, nor by personal uncertainty, $\beta=.19,|t|<1$. As expected, however, a significant interaction between personal uncertainty and the number of aspects manipulation was found, $\beta=-.41, t(51)=-2.17, p<.04$, $\Delta R^{2}=.08$. To further explore this finding, we analyzed simple slopes following suggestions by Aiken and West (1991). For personally certain participants-one standard deviation below the mean—the expected positive, though not significant slope emerged, $\beta=.08,|t|<1$. In contrast, 
for personally uncertain participants—one standard deviation above the mean-a negative slope was observed, $\beta=-.49, t(51)=-2.63, p<.02$; participants who had to identify few as compared to many unfair aspects expected the procedure to be more fair. These findings suggest that the manipulation of accessibility experiences successfully created conditions in which an important antecedent to trust—procedural fairness-is perceived differently, thus setting the stage for differential levels of trustful behavior.

\section{Test of hypotheses}

Our main dependent variable, the amount of money transferred to the other player, was submitted to hierarchical regression analysis. The number of aspects and the centered score of personal uncertainty were entered as predictors in Step 1, and the interaction term was entered in Step 2. The amount of money entrusted to the other player was predicted neither by the number of aspects, $\beta=.15, t(51)=1.12$, $n s$, nor by personal uncertainty, $\beta=.28, t(51)=1.45$, ns. However, supporting our main hypothesis, the interaction between personal uncertainty and number of aspects was significant, $\beta=-.48, t(51)=-2.51, p<.02, \Delta R^{2}=.11$. To further explore this finding, we analyzed simple slopes following the recommendations of Aiken and West (1991), see Figure 2. For personally certain participants—one standard deviation below the mean-a positive slope emerged, $\beta=.48, t(51)=2.61, p<.02$, indicating that participants who had to identify many as compared to few unjust aspects transferred more money to the other player. In line with prior research (e.g., Schwarz, 2004), this suggests that the behavior of personally certain participants was guided by accessibility experiences. For personally uncertain participants—one standard deviation above the mean—-the expected but not significant negative slope was found, $\beta=-.18,|t|<1$. As in Experiment 1 , procedural fairness perceptions and the money trusted to the other player were positively correlated, $r=.21, p<.12$. 
In sum, Experiment 2 was designed to extend the findings reported in Experiment 1 in two ways: First, instead of using a scenario version of the trust game, a behavioral measure was used. Second, to allow for generalization beyond laboratory manipulations, personal uncertainty was not manipulated, but assessed as a continuous score. Despite these changes, results replicate those of Experiment 1, and underscore the general viability of the advanced set of hypotheses.

\section{General Discussion}

Trust has been referred to as a "lubricant" of social systems (Arrow, 1974), allowing close relationships, organizations, and societies to prosper. Prior research focused on identifying antecedents for trust and trustful behavior (e.g., Mayer et al., 1995; McKnight et al., 1998). Much less is known, however, about how these antecedents are integrated to elicit trustful action. The implicit assumption would be that individuals integrate antecedents as content information, such as when counting the number of antecedents. Suggesting a new perspective, we hypothesized that reasons to trust or distrust may influence trustful behavior in a feeling-based summary form. Specifically, we propose that accessibility experiences associated with the identification of antecedents may guide trustful behavior. To investigate these conjectures, two experiments manipulated accessibility experiences associated with the identification of antecedents, and assessed their influence on participants' behavior in the trust game (Berg et al., 1995). Offering coherent evidence, it was demonstrated that accessibility experiences may influence not only judgments and decisions, but also trustful behavior.

In addition to showing that cognitive feelings may guide trustful behavior, the present experiments were designed to shed light on when such an influence may be expected (cf. Spencer et al., 2005, for why this is important). In particular, we hypothesized and found that 
behavior is guided by accessibility experiences in conditions of personal certainty, but content information in conditions of personal uncertainty. Presumably, this is because personal uncertainty increases the likelihood for systematic processing, thus decreasing the impact of cognitive feelings. Again, both experiments corroborated this prediction, thus further explaining the conditions in which accessibility experiences are likely to be of impact.

At least three aspects of the present findings deserve short mention: First, results replicated for both a scenario (Experiment 1) and a factual trust game (Experiment 2). Also, results replicated across an experimental manipulation (Experiment 1) and a continuous measurement (Experiment 2) of personal uncertainty. Presumably, the latter has higher ecological validity. And results replicated across different pay-off structures, in that the amount transferred to the other player was either quadrupled (Experiment 1) or only doubled (Experiment 2). Doubling the entrusted money instead of quadrupling it renders the trust game more conservative, as the incentive to trust is reduced. Together, these experimental variations potently speak to the reliability and generalizability of the reported results.

Second, several precautions were taken to avoid social desirability effects. Participants were repeatedly ensured about anonymity, and care was taken that participants could not reasonably assume that they know the other player, have had an interaction history, or that the experimenter in Experiment 2 could know how much money they entrusted to the other player. Together, it would appear that these precautions successfully created conditions in which participants display trustful behavior.

Third, in both experiments, the pattern of means sustains the conclusion that trustful behavior may be guided by accessibility experiences in conditions of personal certainty. This conclusion was further backed-up by correlational evidence, which revealed that accessibility experiences are negatively related to procedural fairness. These findings cogently support the here advanced hypothesis. 
Finally, although we confined predictions to the expected and theoretically relevant interaction effect, and refrained from specifying the magnitude of single effects, it should be acknowledged that the single effects on procedural justice judgments were not always significant. While this would have been desirable, it appears secondary in light of the fact that clear interactions were observed across variables, and that for the central variable of interestthe amount entrusted to the other player-the simple effects were significant, too.

Going beyond the observed evidence, at least three theoretical notions appear noteworthy. First, while prior research in the domain of trust mainly focused on defining trust and identifying its antecedents and consequences, considerably less is known about how identified antecedents are integrated to guide trustful behavior. The present research extends prior work by allowing for conclusions about the how and the when of this integration. Specifically, it was shown that antecedents may influence trust and trustful behavior either as integrated single pieces of content information in conditions of personal uncertainty, or as feeling-based summaries in conditions of personal certainty.

Second, the present results extend research in the domain of social cognition, which previously focused mainly on the impact of accessibility experiences on judgments, but less on behavior (for exceptions, see Keller \& Bless, 2005; Müller et al., in press). By showing that accessibility experiences may guide behavior, the present results extend the scope of accessibility experiences and further underscore the conclusion that accessibility experiences play an important role in daily life. Indeed, to the extent that accessibility experiences do not only influence judgments and decisions, but also behavior, their impact may be even more important than previously presumed. Given that reliance on accessibility experiences is considered an efficient strategy which produces generally sensible results (Schwarz et al., 2008), this is not an undesirable state. 
Finally, it is interesting to speculate about the psychological underpinnings of personal uncertainty. Presumably, personal uncertainty signals that a specific situation is problematic and therefore warrants attention. Should this problem-signal have triggered the presently observed moderation effect, it would appear that other variables signaling problematic situations may produce similar results. For instance, negative mood states have been suggested to signal problematic situations. Accordingly, one may expect that negative as compared to positive mood states trigger reliance on accessible content information, as observed by Ruder and Bless (2003; see also Greifeneder \& Bless, 2008). Similarly, to the extent that being in power paints the environment more benign, and being powerless signals problems, one would expect that a lack of power increases reliance on accessible content information, as reported by Weick and Guinote (2008). Together, these findings allow for the broader conclusion that accessibility experiences will guide trustful behavior when situations are perceived as benign, but not as problematic. 


\section{References}

Aiken, L. S., \& West, S. G. (1991). Multiple regression: Testing and interpreting interactions. Newbury Park, CA: Sage.

Arrow, K. J. (1974). The limits of organizations. New York: Norton \& Company.

Berg, J., Dickhaut, J., \& McCabe, K. (1995). Trust, Reciprocity, and Social History. Games and Economic Behavior, 10(1), 122-142.

Buchan, N., \& Croson, R. (2004). The boundaries of trust: Own and others' actions in the US and China. Journal of Economic Behavior \& Organization, 55(4), 485-504.

Chaiken, S., \& Trope, Y. (1999). Dual-process theories in social psychology. New York: Guilford Press.

Clore, G. L. (1992). Cognitive phenomenology: Feelings and the construction of judgment. In L. L. Martin \& A. Tesser (Eds.), The construction of social judgments (pp. 133-163). Hillsdale, N.J.: Erlbaum.

Clore, G. L., \& Parrott, W. G. (1994). Cognitive feelings and metacognitive judgements. European Journal of Social Psychology, 24(1), 101-115.

De Cremer, D., \& Sedikides, C. (2005). Self-uncertainty and responsiveness to procedural justice. Journal of Experimental Social Psychology, 41(2), 157-173.

Dijksterhuis, A., Macrae, C. N., \& Haddock, G. (1999). When recollective experiences matter: Subjective ease of retrieval and stereotyping. Personality and Social Psychology Bulletin, 25(6), 760-768.

Dirks, K. T., \& Ferrin, D. L. (2001). The role of trust in organizational settings. Organization Science, 12(4), 450-467.

Festinger, L. (1954). A theory of social comparison processes. Human Relations, 7, 117-140. 
Fukuyama, F. (1995). Trust: the social virtues and the creation of prosperity. New York: Free Press.

Gibbons, F. X., \& Buunk, B. P. (1999). Individual differences in social comparison: Development of a scale of social comparison orientation. Journal of Personality and Social Psychology, 76(1), 129-142.

Greenberg, J. (2006). Losing sleep over organizational injustice: Attenuating insomniac reactions to underpayment inequity with supervisory training in interactional justice. Journal of Applied Psychology, 91(1), 58-69.

Greifeneder, R., \& Bless, H. (2007). Relying on accessible content versus accessibility experiences: The case of processing capacity. Social Cognition, 25(6), 853-881.

Greifeneder, R., \& Bless, H. (2008). Depression and reliance on ease-of-retrieval experiences. European Journal of Social Psychology, 38(2), 213-230.

Greifeneder, R., Bless, H., \& Pham, M. T. (2010). When do people rely on affective and cognitive feelings in judgment? A review. Unpublished manuscript, University of Mannheim.

Greifeneder, R., Müller, P., Stahlberg, D., Van den Bos, K., \& Bless, H. (2009). Beyond procedure's content: Cognitive subjective experiences in procedural justice judgments. Unpublished manuscript, Radboud University Nijmegen, The Netherlands.

Griffin, D. A. (1992). Animal mind. Chicago: The University of Chicago Press.

Haddock, G. (2002). It's easy to like or dislike Tony Blair: Accessibility experiences and the favourability of attitude judgments. British Journal of Psychology, 93(2), 257-267.

Haddock, G., Rothman, A. J., Reber, R., \& Schwarz, N. (1999). Forming judgments of attitude certainty, intensity, and importance: The role of subjective experiences. Personality and Social Psychology Bulletin, 25(7), 771-782.

Hogg, M. A. (2005). Uncertainty, social identity, and ideology. In S. R. Thye \& E. J. Lawler (Eds.), Advances in group processes (Vol. 22). New York: Elsevier. 
Keller, J., \& Bless, H. (2005). When negative expectancies turn into negative performance: The role of ease of retrieval. Journal of Experimental Social Psychology, 41, 535-541.

Knack, S., \& Keefer, P. (1997). Does social capital have an economic payoff? A cross-country investigation. The Quarterly Journal of Economics, 112, 1251-1288.

Koriat, A. (1993). How do we know that we know? The accessibility model of the feeling of knowing. Psychological Review, 100(4), 609-639.

Koriat, A., \& Levy-Sadot, R. (1999). Processes underlying metacognitive judgments: Informationbased and experience-based monitoring of one's own knowledge. In S. Chaiken \& Y. Trope (Eds.), Dual-process theories in social psychology. (pp. 483-502). New York, NY: Guilford Press.

Kramer, R. M. (1999). Trust and distrust in organizations: Emerging perspectives, enduring questions. Annual Review of Psychology, 50, 569-598.

Lind, E. A. (2001). Fairness heuristic theory: Justice judgments as pivotal cognitions in organizational relations. In J. Greenberg \& R. Cropanzano (Eds.), Advances in organization justice (Vol. 56-88). Stanford, CA: Stanford University Press.

Lopes, L. L. (1987). Between hope and fear: The psychology of risk. In L. Berkowitz (Ed.), Advances in experimental social psychology (Vol. 20, pp. 255-295). San Diego, CA: Academic Press.

Mayer, R. C., Davis, J. H., \& Schoorman, F. (1995). An integrative model of organizational trust. Academy of Management Review, 20(3), 709-734.

McGregor, I., Zanna, M. P., Holmes, J. G., \& Spencer, S. J. (2001). Compensatory conviction in the face of personal uncertainty: Going to extremes and being oneself. Journal of Personality and Social Psychology, 80(3), 472-488.

McKnight, D., Cummings, L. L., \& Chervany, N. L. (1998). Initial trust formation in new organizational relationships. Academy of Management Review, 23(3), 473-490. 
Müller, P., Greifeneder, R., Stahlberg, D., Van den Bos, K., \& Bless, H. (in press). Shaping Cooperation Behavior: The Role of Accessibility Experiences. European Journal of Social Psychology.

Novemsky, N., Dhar, R., Schwarz, N., \& Simonson, I. (2007). Preference fluency in consumer choice. Journal of Marketing Research, XLIV, 347-356.

Nowlis, V., \& Nowlis, H. H. (1956). The description and analysis of mood. Annals of the New York Academy of Sciences, 65, 345-355.

Pham, M. T. (2008). The lexicon and grammar of affect-as-information in consumer decision making: The GAIM. In M. Wänke (Ed.), Social Psychology of consumer behavior (pp. 159192). New York: Psychology Press.

Pribram, K. H. (1970). Feelings as monitors. In M. B. Arnold (Ed.), Feelings and emotions (pp. 41-53). New York: Academic Press.

Raghubir, P., \& Menon, G. (1998). AIDS and me, never the twain shall meet: The effects of information accessibility on judgments of risk and advertising effectiveness. Journal of Consumer Research, 25(1), 52-63.

Rothman, A. J., \& Schwarz, N. (1998). Constructing perceptions of vulnerability: Personal relevance and the use of experiential information in health judgments. Personality and Social Psychology Bulletin, 24(10), 1053-1064.

Rotter, J. B. (1966). Generalized expectancies for internal versus external control of reinforcement. Psychological Monographs: General and Applied, 80(1), 1-28.

Ruder, M., \& Bless, H. (2003). Mood and the reliance on the ease of retrieval heuristic. Journal of Personality and Social Psychology, 85(1), 20-32.

Schwartz, B. L. (2002). Tip-of-the-tongue states: Phenomenology, mechanism, and lexical retrieval. Mahwah, NJ: Lawrence Erlbaum Associates. 
Schwarz, N. (1998). Accessible content and accessibility experiences: The interplay of declarative and experiential information in judgment. Personality and Social Psychology Review, 2(2), 87-99.

Schwarz, N. (2004). Metacognitive experiences in consumer judgment and decision making. Journal of Consumer Psychology, 14(4), 332-348.

Schwarz, N., Bless, H., Strack, F., Klumpp, G., Rittenauer-Schatka, H., \& Simons, A. (1991). Ease of retrieval as information: Another look at the availability heuristic. Journal of Personality and Social Psychology, 61(2), 195-202.

Schwarz, N., \& Clore, G. L. (2007). Feelings and phenomenal experiences. In E. T. Higgins \& A. W. Kruglanski (Eds.), Social psychology: Handbook of basic principles (2nd ed., pp. 385407). New York, NY: Guilford Press.

Schwarz, N., Song, H., \& Xu, J. (2008). When thinking is difficult: Metacognitive experiences as information. In M. Wänke (Ed.), Social psychology of consumer behavior (pp. 201-223). New York: Psychology Press.

Spencer, S. J., Zanna, M. P., \& Fong, G. T. (2005). Establishing a causal chain: Why experiments are often more effective than mediational analyses in examining psychological processes. Journal of Personality and Social Psychology, 89(6), 845-851.

Thau, S., Aquino, K., \& Wittek, R. (2007). An extension of uncertainty management theory to the self: The relationship between justice, social comparison orientation, and antisocial work behaviors. Journal of Applied Psychology, 92(1), 250-258.

Tversky, A., \& Kahneman, D. (1973). Availability: A heuristic for judging frequency and probability. Cognitive Psychology, 5(2), 207-232.

Tversky, A., \& Kahneman, D. (1974). Judgment under uncertainty: Heuristics and biases. Science, 185(4157), 1124-1131. 
Van den Bos, K. (2001). Uncertainty management: The influence of uncertainty salience on reactions to perceived procedural fairness. Journal of Personality and Social Psychology, 80(6), 931-941.

Van den Bos, K., Heuven, E., Burger, E., \& Van Veldhuizen, M. F. (2006). Uncertainty Management After Reorganizations: The Ameliorative Effect of Outcome Fairness on Job Uncertainty. Revue Internationale de Psychologie Sociale, 19(1), 75-86.

Van den Bos, K., \& Lind, E. A. (2002). Uncertainty management by means of fairness judgments. In M. P. Zanna (Ed.), Advances in experimental social psychology, Vol. 34 (pp. 1-60). San Diego, CA, US: Academic Press.

Van den Bos, K., \& Lind, E. A. (in press). The social psychology of fairness and the regulation of personal uncertainty. In R. M. Arkin, K. C. Oleson \& P. J. Carroll (Eds.), Handbook of the uncertain self. Mahwah, NJ: Erlbaum Associates.

Van den Bos, K., Poortvliet, P., Maas, M., Miedema, J., \& Van den Ham, E.-J. (2005). An enquiry concerning the principles of cultural norms and values: The impact of uncertainty and mortality salience on reactions to violations and bolstering of cultural worldviews. Journal of Experimental Social Psychology, 41(2), 91-113.

Van den Bos, K., Wilke, H. A., \& Lind, E. A. (1998). When do we need procedural fairness? The role of trust in authority. Journal of Personality and Social Psychology, 75(6), 1449-1458.

Van Lange, P. A. (1999). The pursuit of joint outcomes and equality in outcomes: An integrative model of social value orientation. Journal of Personality and Social Psychology, 77(2), 337349.

Wänke, M., Bless, H., \& Biller, B. (1996). Subjective experience versus content of information in the construction of attitude judgments. Personality and Social Psychology Bulletin, 22(11), $1105-1113$. 
Weick, M., \& Guinote, A. (2008). Power increases reliance on experiential knowledge: Evidence from ease-of-retrieval. Journal of Personality and Social Psychology, 94, 956-970.

Whittlesea, B. W. A. (1993). Illusions of familiarity. Journal of Experimental Psychology: Learning, Memory, and Cognition, 19(6), 1235-1253.

Whittlesea, B. W. A., \& Leboe, J. P. (2000). The heuristic basis of remembering and classification: Fluency, generation, and resemblance. Journal of Experimental Psychology: General, 129(1), 84-106.

Winkielman, P., Schwarz, N., \& Belli, R. F. (1998). The role of ease of retrieval and attribution in memory judgements: Judging your memory as worse despite recalling more events. Psychological Science, 9(2), 124. 


\section{Authors' Note}

The first and second authors have contributed equally and are listed alphabetically. This research was supported by the German Federal Ministry of Education and Research (BMBF) within the framework of the German-Israeli Project Cooperation (DIP) and by a grant from the Deutsche Forschungsgemeinschaft within the Sonderforschungsbereich 504 at the University of Mannheim. 


\section{Footnotes}

1 In the accessibility experiences paradigm, higher ratings of assertiveness after many as compared to few instances of unassertive behavior have been recalled is interpreted as reliance on accessibility experiences (Schwarz et al., 1991; for reviews, Schwarz, 1998; Schwarz, 2004). Alternatively, however, it has been speculated that findings such as these reflect disguised content effects. This argument holds that instances coming to mind later could potentially be of worse quality or of lower extremity than those coming to mind earlier, such that the overall quality or extremity of instances would be different between the few versus many conditions. Extant literature has addressed these reasonable objections with a diverse set of methods (e.g., Ruder \& Bless, 2003; Schwarz et al., 1991; Wänke et al., 1996). However, the outlined alternative explanations do not account for the accrued findings, suggesting that the accessibility experiences paradigm allows for drawing inferences about reliance on accessibility experiences with reasonable confidence. 
Tables

Table 1

Accessibility Experiences Paradigm With Behavioral Implications For Trust Game

Information source

Amount of unfair aspects

Accessibility experiences

Accessible content to be identified

\section{Don't Trust}

Few

("it is easy to identify unfair aspects, so better be careful")

Trust

Many

("it is difficult to identify unfair aspects, so it would appear safe to trust")

\section{Trust}

("there are only few unfair aspects, so it would appear safe to trust")

Don't trust

("there are many unfair aspects, so better be careful")

Notes. Parentheses document potential inferences participants may draw from accessibility experiences versus accessible content information. Accessibility experiences are hypothesized to guide trustful behavior in conditions of personal certainty, whereas accessible content is hypothesized to guide trustful behavior in conditions of personal uncertainty, resulting in the predicted interaction effect. 


\section{Figure Captions}

Figure 1. Mean amount of money entrusted to the receiver (in Euros, with Standard Error) as a function of number of unfair aspects and uncertainty salience versus certainty salience in Experiment 1. Certainty salient conditions are displayed as black bars; uncertainty salient conditions are displayed as grey bars.

Figure 2. Mean amount of money entrusted to the other player (in Euros) as a function of number of unfair aspects and personal uncertainty in Experiment 2. Personally certain individuals (at one standard deviation below the mean) are displayed with a black line; personally uncertain individuals (at one standard deviation above the mean) are displayed with a grey line. 